\title{
The influence of pain-related expectations on intensity perception of non-painful somatosensory stimuli
}

Citation for published version (APA):

Zaman, J., Wiech, K., Claes, N., Van Oudenhove, L., Van Diest, I., \& Vlaeyen, J. W. S. (2018). The influence of pain-related expectations on intensity perception of non-painful somatosensory stimuli. Psychosomatic Medicine, 80(9), 836-844. https://doi.org/10.1097/PSY.0000000000000586

Document status and date:

Published: 01/11/2018

DOI:

10.1097/PSY.0000000000000586

Document Version:

Publisher's PDF, also known as Version of record

Document license:

Taverne

\section{Please check the document version of this publication:}

- A submitted manuscript is the version of the article upon submission and before peer-review. There can be important differences between the submitted version and the official published version of record.

People interested in the research are advised to contact the author for the final version of the publication, or visit the DOI to the publisher's website.

- The final author version and the galley proof are versions of the publication after peer review.

- The final published version features the final layout of the paper including the volume, issue and page numbers.

Link to publication

\footnotetext{
General rights rights.

- You may freely distribute the URL identifying the publication in the public portal. please follow below link for the End User Agreement:

www.umlib.nl/taverne-license

Take down policy

If you believe that this document breaches copyright please contact us at:

repository@maastrichtuniversity.nl

providing details and we will investigate your claim.
}

Copyright and moral rights for the publications made accessible in the public portal are retained by the authors and/or other copyright owners and it is a condition of accessing publications that users recognise and abide by the legal requirements associated with these

- Users may download and print one copy of any publication from the public portal for the purpose of private study or research.

- You may not further distribute the material or use it for any profit-making activity or commercial gain

If the publication is distributed under the terms of Article $25 \mathrm{fa}$ of the Dutch Copyright Act, indicated by the "Taverne" license above, 


\title{
The Influence of Pain-Related Expectations on Intensity Perception of Nonpainful Somatosensory Stimuli
}

\author{
Jonas Zaman, PhD, Katja Wiech, PhD, Nathalie Claes, PhD, Lukas Van Oudenhove, MD, PhD, \\ Ilse Van Diest, PhD, and Johan W.S. Vlaeyen, PhD
}

\begin{abstract}
Objective: The extent to which pain-related expectations, known to affect pain perception, also affect perception of nonpainful sensations remains unclear, as well as the potential role of unpredictability in this context.

Methods: In a proprioceptive fear conditioning paradigm, various arm extension movements were associated with predictable and unpredictable electrocutaneous pain or its absence. During a subsequent test phase, nonpainful electrocutaneous stimuli with a high or low intensity were presented during movement execution. We used hierarchical drift diffusion modeling to examine the influence of expecting pain on the perceptual decision-making process underlying intensity perception of nonpainful sensations. In the first experiment $(n=36)$, the pain stimulus was never presented during the test phase after conditioning. In the second experiment $(n=39)$, partial reinforcement was adopted to prevent extinction of pain expectations.
\end{abstract}

Results: In both experiments, movements that were associated with (un)predictable pain led to higher pain expectancy, self-reported fear, unpleasantness, and arousal as compared with movements that were never paired with pain (effect sizes $\eta_{\mathrm{p}}^{2}$ ranging from 0.119 to 0.557 ; all $p$ values $<.05)$. Only in the second experiment — when the threat of pain remained present — we found that the expectation of pain affected decision making. Compared with the no pain condition, an a priori decision-making bias toward the high-intensity decision threshold was found with the strongest bias during unpredictable pain (effect sizes $\eta_{\mathrm{p}}^{2}$ ranging from 0.469 to 0.504 ; all $p$-values $<.001$ ).

Conclusions: Thus, the expectation of pain affects inferential processes not only for subsequent painful but also for nonpainful bodily stimuli, with unpredictability moderating these effects, and only when the threat of pain remains present due to partial reinforcement.

Key words: pain, expectation, associative fear learning, unpredictability, hierarchical drift diffusion model.

\section{INTRODUCTION}

$T^{1}$ he experience of pain is strongly shaped by expectations. Expecting more or less pain, either through instructions or through learning, can alter the perception of a painful stimulus (1-3). A nociceptive stimulus, for instance, is perceived as more intense when preceded by a cue that predicts high pain as compared with one predicting low pain (4). Although cognitive influences on pain perception have been well documented, their mappings onto the underlying inferential process remain to be elucidated. Computational models including drift diffusion models (DDMs) provide a unique opportunity to differentiate between various mechanisms that shape the inferential process (5). Expectations may not only exert a top-down influence on sensory processes but - at the same time - affect higher-order cortical processes such that the interpretation of sensory input becomes biased (5). For example, using a DDM, cue-induced expectations were shown to bias the perceptual decision-making process toward the expected pain sensation (6) rather than enhancing sensory processing. The generalizability of these effects to nonpainful stimuli has been recently suggested in that they are more likely to be perceived as more intense or even painful because of the expectation of pain (7). In line, Colloca and colleagues ( 2 ) found that electrocutaneous stimuli below pain threshold were rated as painful when presented during the expected occurrence of electrocutaneous pain. Furthermore, the

CS = conditioned stimulus, $\mathbf{D D M}=$ drift diffusion model, $\mathbf{H D D M}=$ hierarchical drift diffusion model, $\mathbf{H M}=$ haptic master, ITI = intertrial interval, $\mathbf{P}=$ predictable, $\mathbf{U}=$ unpredictable, $\mathbf{U S}=$ unconditioned stimulus, VAS $=$ visual analog scale

SDC Supplemental Content

From the Department of Health Psychology (Zaman, Claes, Van Diest, Vlaeyen) and Center for the Psychology of Learning and Experimental Psychopathology (Zaman), Faculty of Psychology and Educational Sciences, KU Leuven, Leuven, Belgium; Centre for Functional Magnetic Resonance Imaging of the Brain (FMRIB) (Wiech) and Nuffield Department of Clinical Neurosciences (Wiech), Nuffield Division Anaesthetics, University of Oxford, John Radcliffe Hospital, Oxford, UK; Tumi Therapeutics (Claes), De Lobbert, Heusden-Zolder, Germany; Laboratory for Brain-Gut Axis Studies (LaBGAS) (Van Oudenhove), Translational Research Centre for Gastrointestinal Disorders (TARGID), Department of Chronic Diseases, Metabolism, and Ageing, KU Leuven; Consultation-Liaison Psychiatry (Van Oudenhove), University Psychiatric Centre KU Leuven, Campus Gasthuisberg, Leuven, Belgium; and Department Clinical Psychological Science (Vlaeyen), Maastricht University, Maastricht, the Netherlands.

Address correspondence to Jonas Zaman, PhD, Health Psychology, KU Leuven, Tiensestraat 102, 3080 Leuven, Belgium. E-mail: onas.zaman@kuleuven.be

Received for publication June 28, 2017; revision received February 22, 2018.

DOI: 10.1097/PSY.0000000000000586

Copyright $\odot 2018$ by the American Psychosomatic Society 
expectation of pain was found to increase the probability of categorizing a stimulus at pain threshold as painful (8). However, the influence of pain-related expectations on the decision-making process underlying intensity perception of nonpainful somatosensory stimuli remains largely unknown. In addition, there has been a renewed interest in the role of unpredictability in the context of cognitive pain modulatory effects. As it stands, it remains unclear whether and how unpredictability affects pain perception. In the literature, hyperalgesia $(9,10)$, hypoalgesia $(11,12)$, and no differences $(12,13)$ have been reported in studies comparing pain reports under unpredictable and predictable pain contexts.

In the current study, we sought to investigate the effect of pain expectations on intensity perception of nonpainful electrocutaneous stimuli in healthy volunteers in predictable and unpredictable pain contexts. In two experiments, a proprioceptive conditioning paradigm was adopted in which arm extension movements served as conditioned stimuli (CSs) and a painful electrocutaneous stimulus as unconditioned stimulus (US). During the test phase, one of two nonpainful electrocutaneous stimuli was presented during movement execution. Participants were requested to categorize these stimuli as either high or low based on their perceived intensity. Response time and accuracy data were used to estimate the different parameters of the decision-making process according to a DDM (see Hierarchical DDM [HDDM]) $(14,15)$. The expectation of pain was hypothesized to result in an a priori decision-making bias similar to the finding of Wiech et al. (6). We had no specific hypotheses about the effect of predictability based on previous mixed findings.

\section{MATERIALS AND METHODS}

\section{Experiment 1}

\section{Participants}

Of the 40 healthy adult volunteers that took part in the study, 36 (26 women) were included in the data analyses because the data of 4 participants were lost due to technical problems (malfunctioning Constant Current Stimulator DS5). Participants were aged between 18 and 40 years (mean $[\mathrm{SD}]$ age $=23.91$ [5.56] years). For more details, see the Supplemental Digital Content 1, http://links.lww.com/PSYMED/A471. All participants provided their written informed consent. The study was approved by the Medical Ethical Committee of the University Hospitals Leuven, Belgium (No. S56566). Data were collected between August 2014 and May 2016.

\section{Electrocutaneous Stimulation}

The stimuli were applied at the distal end of the humerus of the nondominant arm using a commercially available electrocutaneous stimulation device (Constant Current 1 Stimulator, model DS5; Digitimer, Hertfordshire, UK) delivering a 2-millisecond monopolar square waveform pulse via two surface electrodes (V91-01, 8 mm; Coulbourn) filled with K-Y gel (Johnson \& Johnson, New Brunswick, NJ). Stimulation levels were determined for each individual using the Ascending Methods of Limits approach (16). The stimulation intensity was gradually increased until a score of 8 was reached on a visual analog scale (VAS), with the following labels: 0 , no sensation; 1 , weak sensation; 2 , clear sensation; 6 , faint pain; 7, painful; 8 , strong pain but tolerable; and 10, extreme, intolerable pain. During this procedure, three stimulation levels were determined: a nonpainful stimulus of a low intensity $\left(\mathrm{US}_{\mathrm{L}}\right.$; VAS score of 3), a nonpainful stimulus of a higher intensity $\left(\mathrm{US}_{\mathrm{H}}\right.$; VAS score of 5), and a painful stimulus corresponding to a VAS score of 8 $\left(\mathrm{US}_{\mathrm{P}}\right)$. Mean (SD) physical intensities for $\mathrm{US}_{\mathrm{L}}, \mathrm{US}_{\mathrm{H}}$, and $\mathrm{US}_{\mathrm{P}}$ were 17.45 (5.8), 23.45 (7.3), and 34.07 (10.8) mA, respectively. After the initial calibration, $\mathrm{US}_{\mathrm{L}}$ and $\mathrm{US}_{\mathrm{H}}$ were presented once, and participants were informed that these corresponded to the low- and high-intensity "target" stimuli of the subsequent discrimination task. If participants were unable to discriminate both stimuli, intensities were recalibrated using the same calibration protocol. After each test phase (see Procedure), all stimulation intensities we presented and, if necessary based on the obtained VAS ratings, recalibrated.

\section{Proprioceptive Conditioning Paradigm}

Arm extensions were executed with the haptic master (HM), which is a 3-degrees-of-freedom, force-controlled haptic interface (MOOG, NieuwVennep, the Netherlands) enabling movement of a robotic arm along the $x, y$, and $z$ axis, programmed to guide movements. Participants operated the robotic arm with their nondominant hand. The HM restricted movement directions to the horizontal plane, but did not exert any force. Four different movements (two on the participant's left side and two on the right side) were programmed with varying angles (left: 22.5 degrees, 77.5 degrees; right: 112.5 degrees, 157.5 degrees) in the horizontal $(x-z)$ plane, whereas movement distance and starting point were kept constant (Figure 1). Each movement orientation was randomly allocated to one of two conditions. That is, movements in the left hemisphere were allocated to the unpredictable condition, whereas movements in the right hemisphere were allocated to the predictable condition, or vice versa. Within the predictable condition, one of the movements served as the CS+ (i.e., paired with the $\mathrm{US}_{\mathrm{P}}$ ), whereas the other served as the CS- (i.e., predictive of $\mathrm{US}_{\mathrm{P}}$ absence). CS+ allocation was counterbalanced across participants. Within the unpredictable condition, the $\mathrm{US}_{\mathrm{P}}$ could occur pseudo-randomly either during the intertrial interval (ITI) or during each of both movements (labeled $\mathrm{CS}_{\mathrm{U} 1}$ and $\mathrm{CS}_{\mathrm{U} 2}$ ).

\section{Procedure}

The experiment consisted of a practice phase of 10 trials, and four blocks of 44 trials (two predictable $[\mathrm{P}]$ and two unpredictable blocks $[\mathrm{U}]$ ) in pseudorandomized order. The following block orders were used: P-U-U-P, U-PP-U, U-P-U-P, and P-U-P-U. Each block consisted of an acquisition phase and a test phase.

\section{Practice Phase}

After stimulus calibration, participants were familiarized with the HM, the discrimination task, and the startle probes. The practice phase consisted of 10 arm extensions ( 5 with an angle of 45 degrees and 5 with an angle of 135 degrees) during which either $\mathrm{US}_{\mathrm{L}}$ or $\mathrm{US}_{\mathrm{H}}$ was presented (5 times each). ${ }^{1}$ Participants were instructed to categorize the intensity of the stimulus they received as either high or low as fast as possible by pressing corresponding response buttons with their dominant hand. Allocation of responses ("low" and "high") to the response buttons was randomized across participants. During each trial, an acoustic startle probe was presented to allow participants to habituate to this stimulus. Participants were instructed to grab the HM and initiate the movement from the moment the word "START" appeared ( 1.5 seconds) on the screen (see Figure 1). They continued the movement until the word "STOP" appeared on the screen, after which they removed their hand from the HM that then automatically moved back to the start position. Consecutive trials were separated by a 5 -second ITI during which participants looked at the screen for the subsequent start cue to appear. Participants were unaware of movement direction (i.e., no visual information was provided) until they actually exerted force and discovered in which direction they could move. The only visual feedback during a trial was an incrementing timer to help participants pace their movement (the targeted movement duration was 6 seconds). Two artificial boundaries on the extension trajectories were programmed relative to the starting point at 33\% (first boundary) and 66\% (second boundary) of the total distance (Figure 1). Eyeblink startle probes were presented when the first boundary

${ }^{1}$ Different movement angles were used during the practice phase than those used in the experiment. 


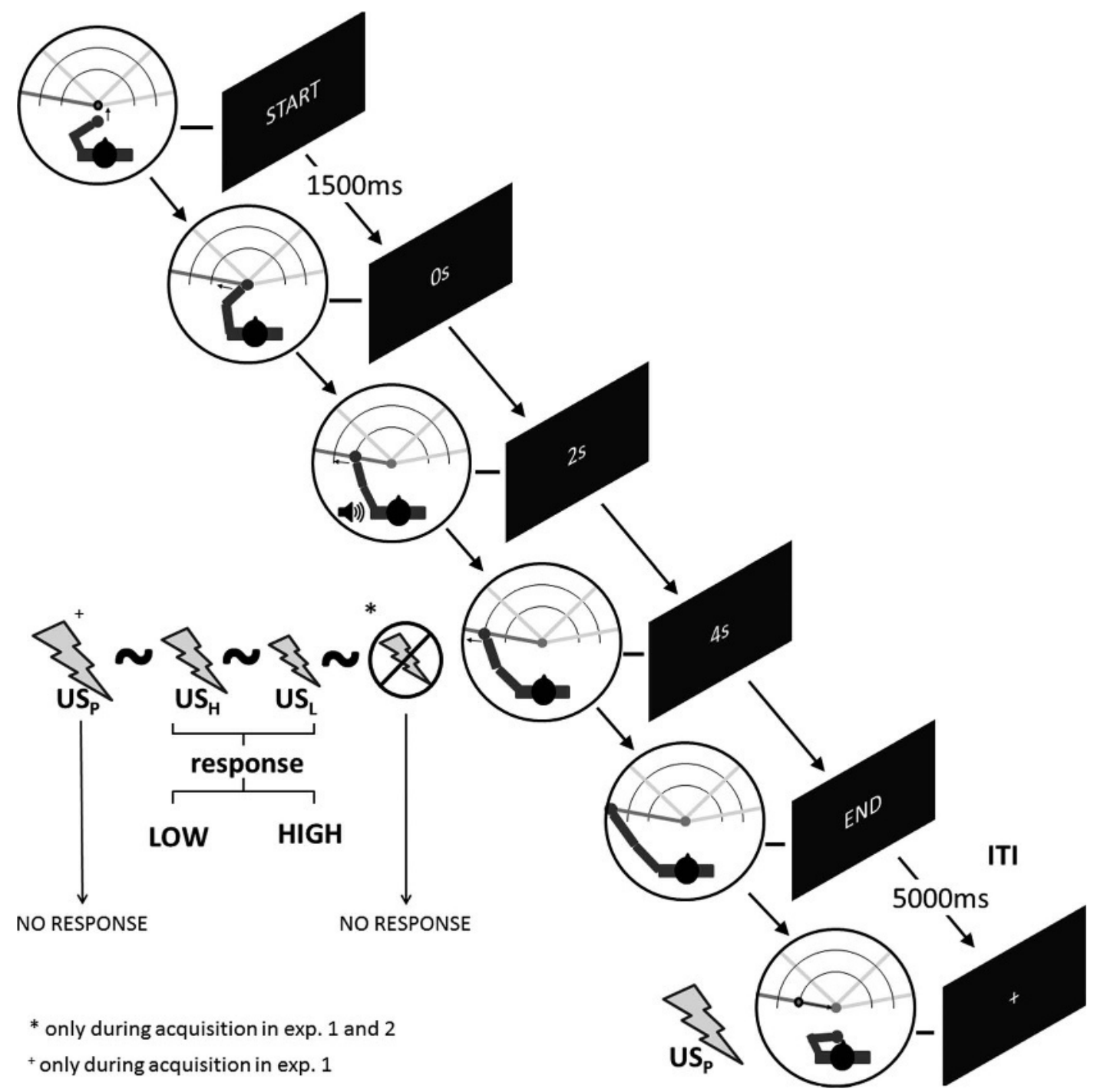

FIGURE 1. Overview of the paradigm. After a start cue, participants grabbed the HM robotic arm and moved it toward the direction guided by the HM. If the trial included a startle probe (indicated by the sound icon), this was presented upon crossing of the first boundary. When the second boundary was reached, the $\mathrm{US}_{\mathrm{P}}, \mathrm{US}_{\mathrm{L}}, \mathrm{US}_{\mathrm{H}}$, or no stimulus were presented depending on the phase and condition. For example, no electrical stimulus was presented during acquisition for some $\mathrm{CS}_{\mathrm{U}}$ and all CS- movements. When the last boundary was reached, participants were instructed to withdraw their hand and the device automatically moved toward the starting position during a 5-seconds ITI, which completed the trial. $\mathrm{HM}=$ haptic master; $\mathrm{US}_{\mathrm{P}}=$ painful stimulus corresponding to a VAS score of 8; $\mathrm{US}_{\mathrm{L}}=$ nonpainful stimulus of a low intensity (VAS score of 3); $\mathrm{US}_{\mathrm{H}}=$ nonpainful stimulus of a higher intensity (VAS score of 5); $\mathrm{CS}=$ conditioned stimulus; $\mathrm{CS}_{\mathrm{U}}=$ conditioned stimulus in the unpredictable context, $\mathrm{ITI}=$ intertrial interval.

was crossed, whereas the electrocutaneous stimuli (i.e., the $\mathrm{US}_{\mathrm{p}}, \mathrm{US}_{\mathrm{L}}$, and $\mathrm{US}_{\mathrm{H}}$ ) were presented upon crossing the second boundary. Whenever participants crossed the first boundary within less than 2 seconds, the warning "Too fast" appeared on the screen at the end of the trial, and the trial was put back into the trial pool to be repeated.

\section{Acquisition Phase}

During this phase, participants were instructed that they were to perform the movements without the discrimination task and that painful electrocutaneous stimuli $\left(\mathrm{US}_{\mathrm{P}}\right.$ ) could be applied. Depending on the condition, the background of the screen changed from black to either blue or orange depending on the type of block (predictable versus unpredictable). Color allocation to the different conditions was counterbalanced.

\section{Acquisition-Predictable Context}

This phase consisted of six CS+ movements and six CS- movements. All $\mathrm{CS}+$ movements were followed by the $\mathrm{US}_{\mathrm{P}}(100 \%$ contingency). For the CStrials, no electrocutaneous stimuli were applied. In $50 \%$ of both the CS+ and $\mathrm{CS}-$ trials, a startle probe was presented.

\section{Acquisition-Unpredictable Context}

This phase consisted of six $\mathrm{CS}_{\mathrm{U} 1}$ and six $\mathrm{CS}_{\mathrm{U} 2}$ movements. The $\mathrm{US}_{\mathrm{P}}$ was presented during movement execution (two $\mathrm{CS}_{\mathrm{U} 1}$ and two $\mathrm{CS}_{\mathrm{U} 2}$ trials) and during the ITI ( $1 \mathrm{CS}_{\mathrm{U} 1}$ and $1 \mathrm{CS}_{\mathrm{U} 2}$ trial) in $33 \%$ and $16 \%$ of the trials, respectively. In the remaining trials, no electrocutaneous stimuli were applied. In $50 \%$ of the trials, an acoustic startle probe was presented.

At the end of each acquisition phase, self-reported US expectancy ("0" no expectation of pain, " 100 " high expectation of pain), fear (" 0 " no fear, 
"100" very fearful), unpleasantness (" 0 " not unpleasant, " 100 " very unpleasant), and tension (" 0 " no tension, " 100 " very tensed) using VAS scales were obtained via the response buttons. The questions were presented in a randomized order.

\section{Test Phase}

During the test phase, no painful stimuli $\left(\mathrm{US}_{\mathrm{P}}\right)$ were delivered anymore. Participants were instructed that during this phase, the low- and highintensity stimuli could be presented and that they had to categorize them accordingly. They were not explicitly instructed that the pain US would no longer be presented during test phase. The background of the screen remained the same as that during the acquisition phase. Depending on the type of acquisition block (i.e., predictable or unpredictable), there are two types of test blocks. Note that each type of acquisition block was always followed by the corresponding test block

\section{Test-Predictable Context}

This block consisted of $16 \mathrm{CS}+$ and $16 \mathrm{CS}-$ movements. In $50 \%$ of the $\mathrm{CS}-$ and $\mathrm{CS}+$ trials, $\mathrm{US}_{\mathrm{L}}$ was presented, whereas in the remaining $8 \mathrm{CS}-$ and $8 \mathrm{CS}+$ trials, $\mathrm{US}_{\mathrm{H}}$ was presented. A startle probe was presented in $50 \%$ of the $\mathrm{CS}+$ and $\mathrm{CS}-$ trials

\section{Test-Unpredictable Context}

This block consisted of $16 \mathrm{CSu}_{1}$ and $16 \mathrm{CSu}_{2}$ movements. In $50 \%$ of the $\mathrm{CS}_{\mathrm{u}}$ trials, $\mathrm{US}_{\mathrm{L}}$ was presented, whereas in the remaining trials, $\mathrm{US}_{\mathrm{H}}$ was presented. An acoustic startle probe was presented in $50 \%$ of the trials.

\section{Eyeblink Startle Responses}

Orbicularis oculi electromyographic activity was recorded using three $\mathrm{Ag}$ / $\mathrm{AgCl}$ electrodes (V91-02, $4 \mathrm{~mm}$; Coulbourn), according to the guidelines described by Blumenthal et al. (17). For more details, see the Supplemental Digital Content 1, http://links.lww.com/PSYMED/A471. Startle data from three participants were excluded due to excessive noise. None of the participants met the criteria of nonresponder ( $\%$ nonresponses $>50 \%$ of trials) To reduce interindividual variation, startle amplitudes were transformed into $T$ scores, and mean startle amplitudes were calculated per phase and CS. If a mean was based on fewer than four observations, it was coded as a missing value ( $1 \%$ of the data cells).

\section{Experiment 2}

Experiment 2 consists of a small adaptation of the protocol of Experiment 1. We only describe the differences with Experiment 1.

\section{Participants}

Thirty-nine healthy adult volunteers ( 25 women) took part in the study and were included in the data analyses. Participants were aged between 18 and $40($ mean $[\mathrm{SD}]$ age $=24.31[5.25])$

\section{Electrocutaneous Stimulation}

Mean (SD) intensities for $\mathrm{US}_{\mathrm{L}}, \mathrm{US}_{\mathrm{H}}$, and the $\mathrm{US}_{\mathrm{P}}$ were 12.53 (4.6), 19.75 (8.28), and 27.43 (11.87) $\mathrm{mA}$, respectively.

\section{Procedure}

The procedure was identical to Experiment 1 except that the $U_{\mathrm{P}}$ could now be administered during the test phase. Before the test phase, participants were instructed that in addition to the pain stimulus $\left(\mathrm{US}_{\mathrm{P}}\right)$, either the low- or the high-intensity "target" stimuli could be presented, and that they should refrain from responding when the painful stimulus $\left(\mathrm{US}_{\mathrm{P}}\right)$ occurred.

Test-Predictable Context. This phase consisted of $24 \mathrm{CS}+$ and 16 CS- movements. Eight CS+ movements were reinforced by the $\mathrm{US}_{\mathrm{P}}$ $(33 \%)$. In $50 \%$ of the CS- trials and half of the remaining $16 \mathrm{CS}+$ trials, $\mathrm{US}_{\mathrm{L}}$ was presented, whereas in the other $8 \mathrm{CS}-$ and $8 \mathrm{CS}+$ trials, $\mathrm{US}_{\mathrm{H}}$ was presented. An acoustic startle probe was presented in $50 \%$ of the $\mathrm{CS}+$ and $\mathrm{CS}-$ trials.

Test-Unpredictable Context. This phase consisted of $20 \mathrm{CS}_{\mathrm{U} 1}$ and $20 \mathrm{CS}_{\mathrm{U} 2}$ movements. In $10 \%$ of the trials, $\mathrm{US}_{\mathrm{P}}$ was presented during the movement $\left(2 \mathrm{CS}_{\mathrm{U} 1}\right.$ and $2 \mathrm{CS}_{\mathrm{U} 2}$ trials), and in $10 \%$ of the trials, $\mathrm{US}_{\mathrm{P}}$ was presented during the ITI ( $2 \mathrm{CS}_{\mathrm{U} 1}$ an $2 \mathrm{CS}_{\mathrm{U} 2}$ trials). In $50 \%$ of the remaining $16 \mathrm{CS}_{\mathrm{U} 1}$ and $16 \mathrm{CS}_{\mathrm{U} 2}$ trials, $\mathrm{US}_{\mathrm{L}}$ was presented, whereas in the other trials, $\mathrm{US}_{\mathrm{H}}$ was presented. In $50 \%$ of the $\mathrm{CS}_{\mathrm{U} 1}$ and $\mathrm{CS}_{\mathrm{U} 2}$ trials, a startle probe was presented.

\section{Eyeblink Startle Responses}

Because of technical difficulties (i.e., malfunctioning Coulbourn integrator), eyeblink startle recordings were excluded from further analyses.

\section{Hierarchical DDM}

DDMs are sequential sampling models where (binary) decision-making is considered an active inferential process based on the accumulation of information across time $(14,18)$. They are applied to two-alternative forced choice data using response time distributions of both correct and incorrect responses as input (combining mean response time, the variance, and decision accuracy). The DDM assumes that information favoring each possible response is integrated over time and that a decision is made when the accumulated information reaches a certain threshold (18) (Figure 2). The speed of evidence accumulation, called the drift rate $(v)$, has been suggested as a proxy of sensory processing (6), with manipulations in stimulus quality affecting drift rate $(18,20)$. Larger drift rates indicate faster evidence accumulation. The alternative responses are represented by two orthogonal decision thresholds. The distance between these thresholds, called boundary separation $(a)$, determines decision conservativeness (i.e., the critical amount of information that the observer requires). The larger the boundary separation, the more evidence is required by the observer. For example, emphasizing accuracy or speed has been found to affect this parameter $(20,21)$. The start point of the accumulation process is affected by expectations $(6,22)$ and can therefore be shifted toward one of the two decision thresholds, such that less information needs to accumulate to make a certain decision, thus reflecting an a priori decision-making bias (for more details, see Refs. $(14,18)$ ).

Response time and accuracy data were entered in an HDDM using a Python-based algorithm (http://ski.clps.brown.edu/hddm docs; Wiecki et al. (14)). ${ }^{2}$ Trials with a response time \pm 2 SD or less than 200 milliseconds were removed (approx. $4.3 \%$ of each participant's data) before model fitting (23). Hierarchical models - compared with the traditional diffusion models - require fewer data points per participant because they allow parameters from each individual to be drawn from a group distribution (15). The following parameters (see Figure7 2) of the HDDM were modeled (19) (for more details, see the Supplemental Digital Content 1, http://links.lww.com/PSYMED/A471): Drift rate was allowed to vary between conditions $\left(\mathrm{CS}+/ \mathrm{CS}-/ \mathrm{CS}_{\mathrm{u}}\right)$ and stimuli $\left(\mathrm{US}_{\mathrm{L}} / \mathrm{US}_{\mathrm{H}}\right)$. Boundary separation and starting point were allowed to vary only between conditions $\left(\mathrm{CS}+/ \mathrm{CS}-/ \mathrm{CS}_{\mathrm{u}}\right)$. Finally, the nondecision time parameter that combines the time required for stimulus encoding with the time required for execution of the response - that is, total response time excluding the time required for decision making $\left(T_{\mathrm{er}}\right)$-was kept fixed across conditions and stimuli. Only intertrial variability was allowed for the nondecision component $\left(S_{t}\right)(24)$.

\section{Data Analyses}

Planned contrasts using repeated-measures ANOVA (one within-subject factor condition: $\mathrm{CS}_{\mathrm{U}} / \mathrm{CS}+/ \mathrm{CS}-$ ) were used to test for all self-report ratings and startle orbicularis oculi electromyographic activity recordings whether the $\mathrm{CS}+$ elicited the highest response relative to the $\mathrm{CS}_{\mathrm{U}}$ and $\mathrm{CS}-$ with

\footnotetext{
${ }^{2}$ The output of the repeated-measures analysis of variance (ANOVA) for the two-alternative forced choice data can be found in the Supplemental Information. (Supplemental Digital Content 1, http://links.lww.com/PSYMED/A471
} 

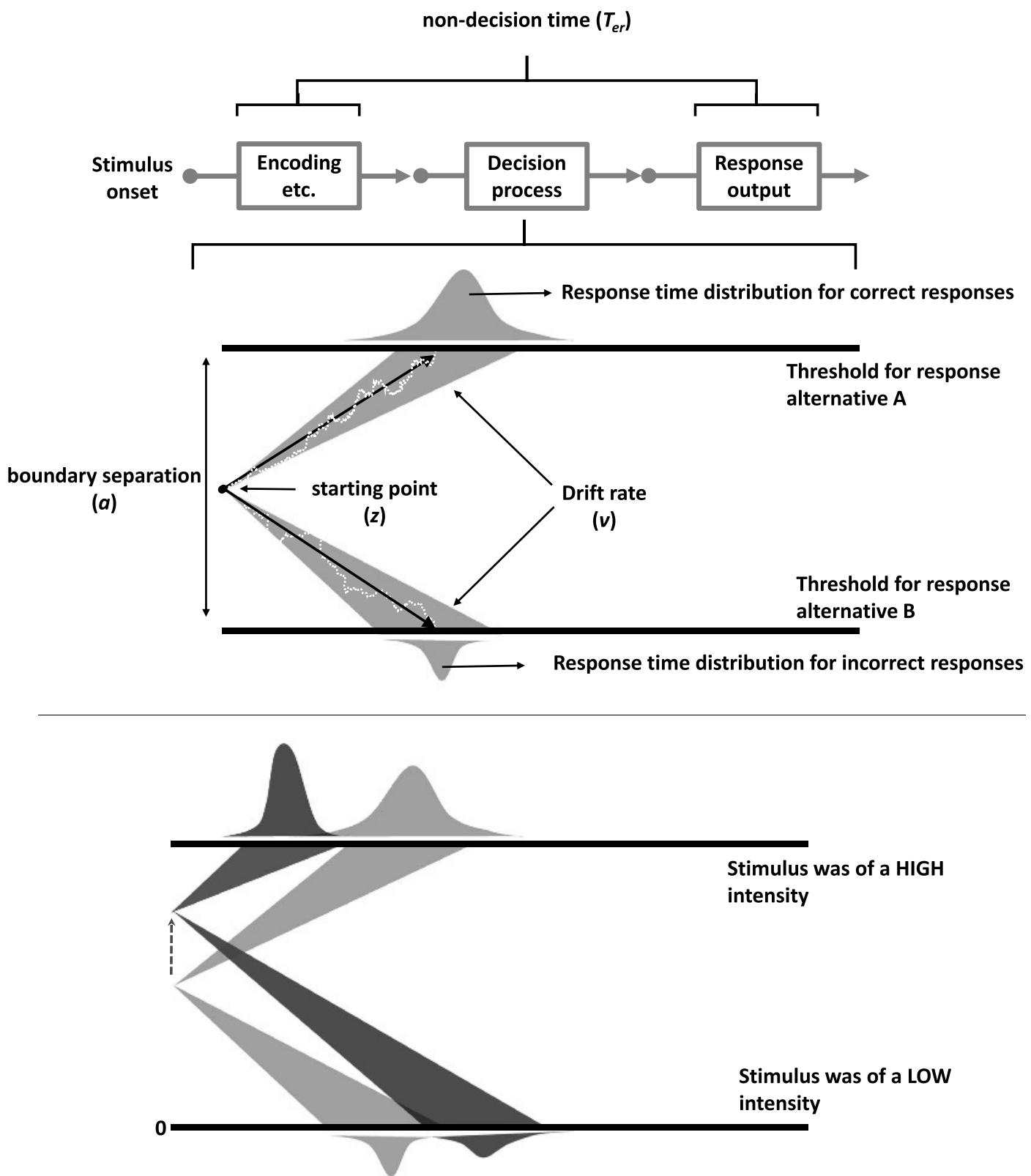

FIGURE 2. Overview of the drift diffusion model. Top panel: according to these models, perception is a stochastic process characterized by accumulation of noisy sensory input until a decision boundary is reached (18). The decision process consists of the accumulation of evidence (i.e., speed of information accumulation called drift rate [v]) from a certain starting point (i.e., an a priori bias [z]) until one of two decision thresholds is reached and a response is executed. The distance between the orthogonal decision thresholds is called the boundary separation $(a)$ and represents the decision conservativeness (i.e., how much evidence is required to make a decision). The nondecision component $\left(T_{\mathrm{er}}\right)$ comprises the time required for stimulus encoding and response execution. The white dotted lines represent a single accumulation trace of evidence, which is a noisy process. Bottom panel: the dark gray illustrates the effect of a shift in starting point (z) from the midpoint (no bias) toward the high-intensity threshold on the response times distributions. Because of this shift in starting point, less evidence is required to categorize the stimulus as "high" and the probability of high-intensity percepts increases. Adapted with permission from Zaman et al. (19).

higher responses for the $\mathrm{CS}_{\mathrm{U}}$ compared with the $\mathrm{CS}-$ (similar to the finding of Meulders et al. (25)). The estimated individual drift diffusion parameters were entered in repeated-measures ANOVAs with condition $\left(\mathrm{CS}_{\mathrm{u}} / \mathrm{CS}+/ \mathrm{CS}-\right)$ as within-subject factor (for the parameters starting point and boundary separation). For the parameter drift rate, stimulus $\left(\mathrm{US}_{\mathrm{L}} / \mathrm{US}_{\mathrm{H}}\right)$, and the interaction with condition were included as well. Greenhouse-Geisser corrections were applied whenever the sphericity assumption was unmet.
Uncorrected degrees of freedom and corrected $p$ values are reported together with $\varepsilon$. Partial squared eta $\left(\eta_{\mathrm{p}}^{2}\right)$ effect sizes are reported for the ANOVAs, with small, medium, and large effects corresponding to values of $0.0099,0.0588$, and 0.1379 , according to Cohen (17). Concerning the HDDM parameters, we expected the highest starting point for the CS+ compared with the $\mathrm{CS}_{\mathrm{U}}$ (i.e., located closer to the high-intensity decision threshold), reflective of an a priori decision-making bias, and the lowest 


\section{Experiment 1}

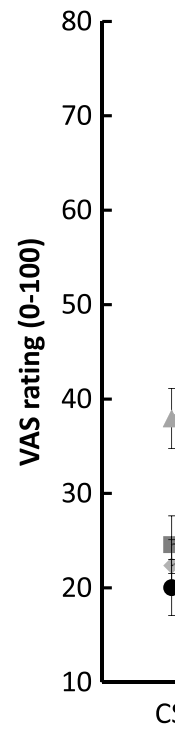

\section{Experiment 2}

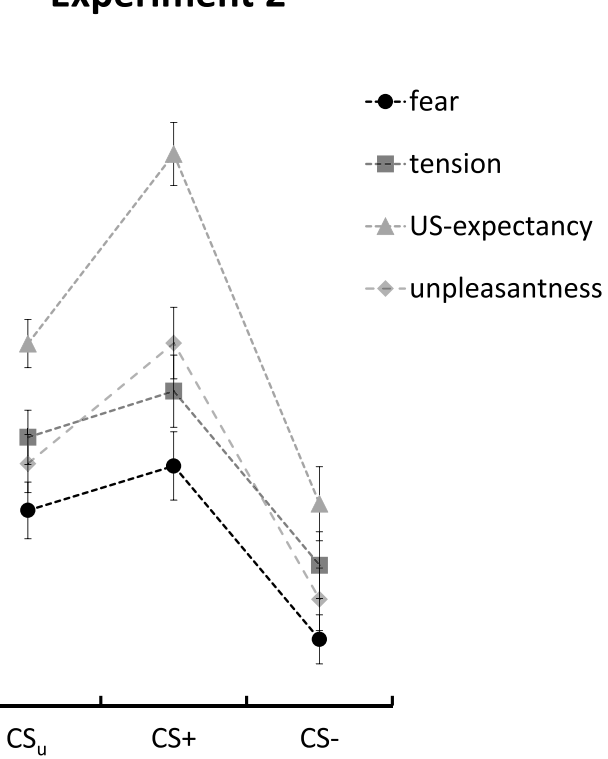

FIGURE 3. Mean retrospective self-report ratings for US expectancy, fear, arousal, and unpleasantness with standard errors. VAS $=$ visual analog scale; $\mathrm{US}=$ unconditioned stimulus; $\mathrm{CS}_{\mathrm{U}}=$ conditioned stimulus in the unpredictable context; $\mathrm{CS}+/ \mathrm{CS}-=$ conditioned stimulus paired with the $\mathrm{US}_{\mathrm{P}} /$ absence of $\mathrm{US}_{\mathrm{P}} ; \mathrm{US}_{\mathrm{P}}=$ painful stimulus corresponding to a VAS score of 8.

starting point for the $\mathrm{CS}-$ compared with the $\mathrm{CS}_{\mathrm{U}}$ (i.e., located closer to the low intensity decision threshold) (6). No difference in boundary separation between CSs was expected (i.e., no difference in decision conservativeness). For drift rate, a larger drift rate for $\mathrm{US}_{\mathrm{L}}$ compared with $\mathrm{US}_{\mathrm{H}}$ was expected (6), indicative of faster evidence accumulation.

\section{RESULTS}

\section{Experiment 1}

\section{Subjective Ratings}

Planned contrasts revealed that the CS+ compared with the CSwas rated higher on US expectancy $(F(1,35)=31.92, p<.001$, $\left.\eta_{\mathrm{p}}^{2}=0.477\right)$, fear $\left(F(1,35)=34.23, p<.001, \eta_{\mathrm{p}}^{2}=0.494\right)$, arousal $\left(F(1,35)=15.70, p<.001, \eta_{\mathrm{p}}^{2}=0.310\right)$, and unpleasantness $\left(F(1,35)=44.00, p<.001, \eta_{\mathrm{p}}^{2}=0.557\right.$; Figure 3$)$. Similarly, the $\mathrm{CS}_{\mathrm{U}}$ compared with the CS- led to higher self-reported US expec$\operatorname{tancy}\left(F(1,35)=19.00, p<.001, \eta_{\mathrm{p}}^{2}=0.352\right)$, fear $(F(1,35)=25.23$, $\left.p<.001, \eta_{\mathrm{p}}^{2}=0.419\right)$, arousal $\left(F(1,35)=14.93, p<.001, \eta_{\mathrm{p}}^{2}=0.299\right)$, and unpleasantness levels $\left(F(1,35)=20.66, p<.001, \eta_{\mathrm{p}}^{2}=0.371\right)$. The CS + did not differ from the $\mathrm{CS}_{\mathrm{U}}$ on arousal $(F(1,35)=1.73$, $p=.19)$ and fear $(F(1,35)=1.97, p=.17)$, whereas the CS+ was rated significantly higher on US expectancy $(F(1,35)=25.28$, $\left.p<.001, \eta_{\mathrm{p}}^{2}=0.419\right)$ and unpleasantness $(F(1,35)=24.38$, $p<.001, \eta_{\mathrm{p}}^{2}=0.411$; see Figure 3 ).

\section{Eyeblink Startle Responses}

Planned contrasts revealed no significant differences in startle amplitudes during the CS + compared with the CS- $(F(1,31)=3.1$, $\left.p=.088, \eta_{\mathrm{p}}^{2}=0.091\right)$. There was no difference between the CS+ and the $\operatorname{CS}_{\mathrm{U}}(F(1,31)=1.97, p=.17)$ or between the $\mathrm{CS}_{\mathrm{U}}$ and the $C S-(F(1,31)=0.001, p=.98)$.

\section{HDDM Parameter Estimates}

Contrary to our expectations, the CSs did not differ in the starting point of the evidence accumulation process $(F(2,70)=2.62$, $p=.080, \eta_{\mathrm{p}}^{2}=0.070$; Figure 4). There was no difference between the CSs regarding the distance between the two decision thresholds (i.e., boundary separation; $F(2,70)=1.25, p=.29$ ). As expected, we did find overall larger drift rates (main effect of stimulus: $F(1,35)=136,46, p<.001, \eta_{\mathrm{p}}^{2}=0.796$, indicative of faster evidence accumulation) for $\mathrm{US}_{\mathrm{L}}$ compared with $\mathrm{US}_{\mathrm{H}}$ (Figure 4). Furthermore, we found a main effect of condition on drift rate $\left(F(2,70)=3.23, p=.046, \eta_{\mathrm{p}}^{2}=0.084\right)$. Only drift rates were larger during the CS+ compared with the CS- $(F(1,35)=6.46$, $\left.p=.032,{ }^{3} \eta_{\mathrm{p}}^{2}=0.156\right)$. The interaction between stimulus and condition did not reach statistical significance $(F(2,70)=1.65, p=.20)$.

\section{Experiment 2}

\section{Subjective Ratings}

Similar to Experiment 1, planned contrasts revealed that the CS+ compared with the CS- was rated higher on US expectancy $\left(F(1,38)=17.95, p<.001, \eta_{\mathrm{p}}^{2}=0.321\right)$, fear $(F(1,38)=14.20$, $\left.p=.001, \eta_{\mathrm{p}}^{2}=0.272\right), \operatorname{arousal}\left(F(1,38)=8.19, p=.007, \eta_{\mathrm{p}}^{2}=0.177\right)$, and unpleasantness $\left(F(1,38)=11.29, p=.002, \eta_{\mathrm{p}}^{2}=0.229\right.$; Figure 3). In line with findings from Experiment 1, the $\mathrm{CS}_{\mathrm{U}}$ compared with the CS- led to higher self-reported US expectancy $\left(F(1,38)=5.15, p=.029, \eta_{\mathrm{p}}^{2}=0.119\right)$, fear $(F(1,38)=9.64$, $\left.p=.004, \eta_{\mathrm{p}}^{2}=0.202\right)$, arousal $\left(F(1,38)=7.46, p=.010, \eta_{\mathrm{p}}^{2}=0.164\right)$, and unpleasantness levels $\left(F(1,38)=5.416, p=.025, \eta_{\mathrm{p}}^{2}=0.125\right)$. Comparison of the $\mathrm{CS}+$ with the $\mathrm{CS}_{\mathrm{U}}$ revealed a similar pattern to that in Experiment 1; $\mathrm{CS}_{\mathrm{U}}$ movements did not differ from the CS+ in arousal $(F(1,38)=2.11, p=.16)$ and fear $(F(1,38)=3.74$, $\left.p=.061, \eta_{\mathrm{p}}^{2}=0.090\right)$, whereas they were rated significantly lower on US expectancy $\left(F(1,38)=17.08, p<.001, \eta_{\mathrm{p}}^{2}=0.310\right)$ and unpleasantness $\left(F(1,38)=6.13, p=.018, \eta_{\mathrm{p}}^{2}=0.139\right.$; see Figure 3$)$.

${ }^{3}$ Corrected for multiple testing using an adjusted Bonferroni correction of factor 2 . 
EXPERIMENT 1

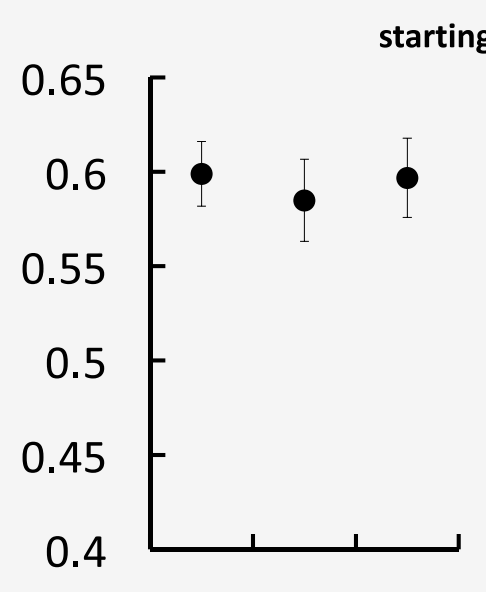

$\mathrm{CSu}$ CS+ CS-

\section{EXPERIMENT 2}
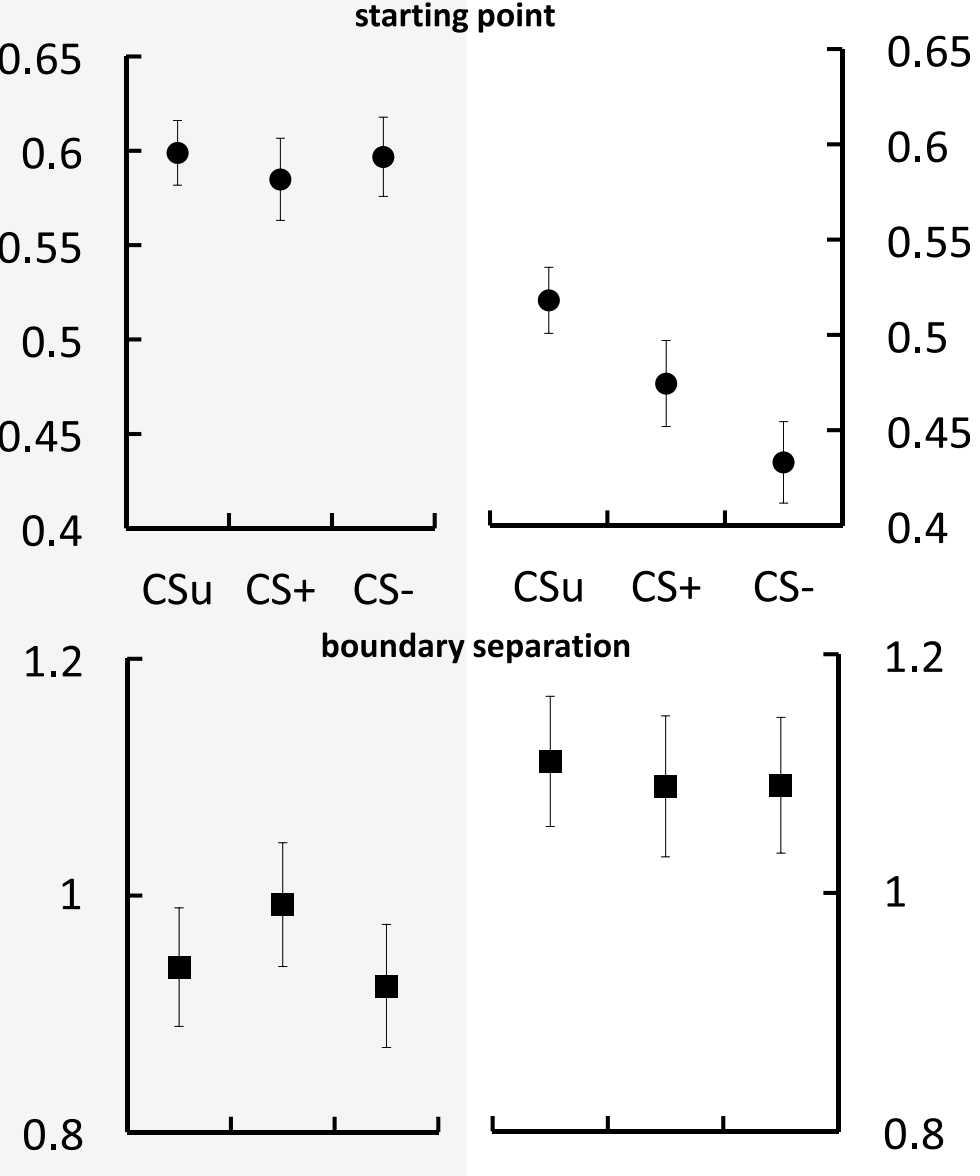

$\mathrm{CSu} \mathrm{CS}+\mathrm{CS}-\mathrm{CSu} \mathrm{CS}+\mathrm{CS}-$

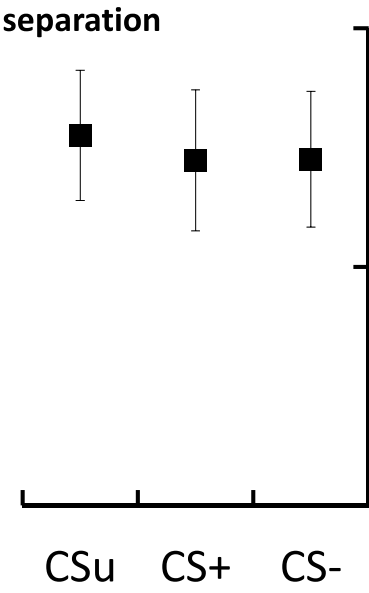

1

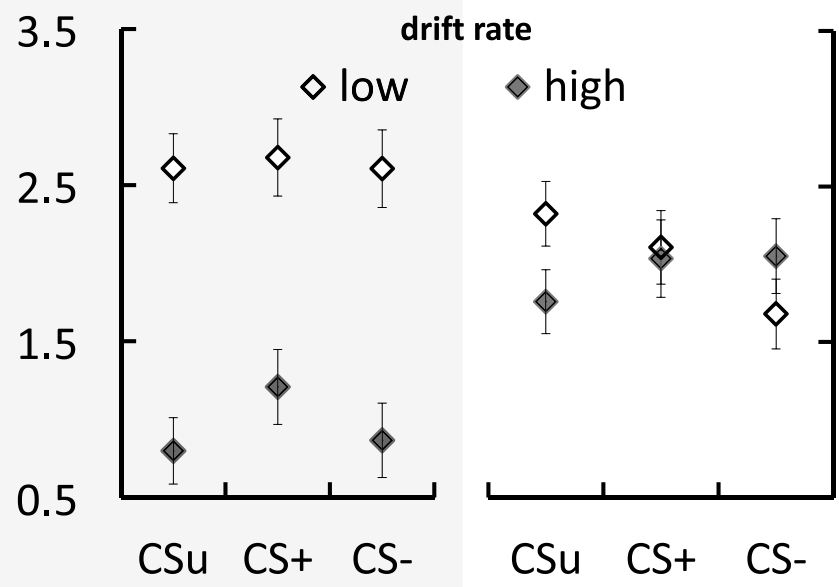

3.5

2.5

1.5

0.5

FIGURE 4. Mean drift diffusion parameter estimates with standard deviations. $\mathrm{CS}_{\mathrm{U}}=$ conditioned stimulus in the unpredictable context; $\mathrm{CS}+/ \mathrm{CS}-=$ conditioned stimulus paired with the $\mathrm{US}_{\mathrm{P}} /$ absence of $\mathrm{US}_{\mathrm{P}} ; \mathrm{US}_{\mathrm{P}}=$ painful stimulus corresponding to a VAS score of 8.

\section{HDDM Parameter Estimates}

We found a main effect of condition on starting point $\left(F(2,76)=72.17, p<.001, \eta_{\mathrm{p}}^{2}=0.655\right)$. Contrary to our expectations, the $\mathrm{CS}_{\mathrm{U}}$ led to a higher starting point compared with the $\mathrm{CS}+\left(F(1,38)=33.57, p<.001, \eta_{\mathrm{p}}^{2}=0.469\right)$; the starting point was lower for the CS- compared with the CS+ $(F(1,38)=38.56$, $p<.001, \eta_{\mathrm{p}}^{2}=0.504$; see Figure 4$)$. For boundary separation, as expected, no differences between the CSs were found $(F(2,76)=0.132, p=.84, \varepsilon=.817)$. Contrary to our hypotheses, no main effect of stimulus on drift rates was observed 
$(F(1,38)=0.381, p=.54)$. We found a main effect of condition $\left(F(1,76)=3.14, p=.049, \eta_{\mathrm{p}}^{2}=0.076\right)$, but none of the post hoc tests $^{3}$ survived the multiple testing correction ( $p$ values $\left.>.057\right)$. The significant condition by stimulus $\left(F(1,76)=25.22, p<.001, \eta_{\mathrm{p}}^{2}=0.399\right)$ was driven by larger drift rates during US $\mathrm{U}_{\mathrm{L}}$ compared with $\mathrm{US}_{\mathrm{H}}$ for $\mathrm{CS}_{\mathrm{U}}\left(F(1,38)=11.31, p=.004^{3}, \eta_{\mathrm{p}}^{2}=0.229\right)$, whereas for the CS+ and $\mathrm{CS}-$, no difference in drift rates between the stimuli was observed after correction for multiple testing $\left(p\right.$ values $\left.>.063^{3}\right)$.

\section{DISCUSSION}

Using a computational model (14), the effects of pain expectations on the perceived intensity of nonpainful somatosensory stimuli were assessed. In both experiments, a proprioceptive fear conditioning paradigm was adopted to induce different expectations about the probability of pain occurrence. Self-reported US expectancy ratings showed that participants learned the association between certain movements and the occurrence of the painful electrocutaneous stimuli. During the subsequent test phase, electrocutaneous stimuli of different intensities below pain threshold were presented instead of the expected painful electrocutaneous stimulus.

An HDDM was used to differentiate between various types of decision-making biases based on the response time distributions of (in)correct responses. Although in both experiments, participants learned the relationship between certain movements and the probability of pain occurrence, the decision-making process underlying intensity perception did not differ between conditions in Experiment 1 . That is, neither predictable nor unpredictable pain elicited a shift in starting point toward the high-intensity threshold compared with the no pain condition; nor did they affect any of the other decision-making parameters. However, since the pain US was never presented during the test phase of this experiment, it is possible that participants adjusted their expectations accordingly as they learned that the pain US no longer occurred. Furthermore, repeated exposure to CSs in the absence of a US is known to extinguish fear responses (26), which may have prevented perceptual changes as, for example, enhanced fear responding has been proposed to mediate conditioned allodynia (27). In the second experiment, partial reinforcement was adopted during the test phase, similar to Ref. (28), to prevent extinction of pain expectations and pain-related fear. Contrary to Experiment 1, we found effects of predictable and unpredictable pain on perceptual decision making, as the starting point shifted upward compared with the no pain condition, with the strongest shift toward the high-intensity decision threshold for unpredictable pain. Thus, when the threat of pain remained present, the effects of expecting pain generalized to the inferential process concerning intensity perception of nonpainful stimuli. Similar to the work of Wiech and colleagues (6), we found that pain-related expectations affected the starting point of the decision-making process, indicative of an inferential bias, rather than other processes (such as sensory processing [drift rate] or decision conservativeness [boundary separation]). In other words, before any incoming nonpainful sensory input, a bias emerged that favored the high-intensity percept. Consequently, participants required less evidence (or sensory noise) to reach the corresponding decision threshold. However, contrary to the study of Wiech et al., we found the strongest decision-making bias during unpredictable pain. In the study of Wiech et al., both prior expectations and decision making involved painful stimuli, whereas our categorization task involved two nonpainful somatosensory stimuli. One potential explanation is that the expectation of pain in the unpredictable condition is characterized by a low probability of occurrence (i.e., US expectancy ratings) and hence is less affected upon presentation of stimuli that violate the expectation, resulting in a relatively low prediction error and updating of the expectation. The current findings extend the observation that unpredictable pain led to higher-intensity ratings of a heat stimulus below pain threshold (11) and suggest that biased perceptual decision making might underlie such effects. Furthermore, the expected absence of an effect of pain expectations upon decision conservativeness (i.e., boundary separation) suggests that differences in the probability of pain occurrence do not alter the amount of evidence needed to make a decision.

Despite these intriguing findings, some limitations should be acknowledged. Although our paradigm consisted of a two-forced choice task, the instruction - in Experiment 2- to refrain from responding in the case of the US made it an implicit three-forced choice task. Future studies should explore to which extent this affected parameter estimates. For example, the higher percentage of omitted responses for $\mathrm{US}_{\mathrm{H}}$ (see Supplemental Digital Content 1, http://links.lww.com/PSYMED/A471) might provide an explanation for the overall lower estimated starting points in Experiment 2. However, because omitted responses did not differ between conditions (see Supplemental Digital Content 1, http://links.lww. com/PSYMED/A471), it seems unlikely that differences between conditions can be attributed hereto.

In sum, the current study demonstrates that expecting pain exerts an influence on somatosensory perception when the threat of pain remains present. Thus, the expectation of pain affects inferential processes about not only subsequent painful but also nonpainful bodily stimuli, and the degree of unpredictability may strengthen these effects. As such, in individuals with chronic pain, the (un)predictability of their pain (7) might bias them to process bodily sensations as more intense and potentially painful.

We thank Lora Masui and Hanne Hertogen for help with data collection.

Source of Funding and Conflicts of Interest: This work was supported by research grants G054309 (I.V.D.), G091812 (N.C.), and the Odysseus research program "Pain and Disability" (J.V.) funded by the Research Foundation, Flanders, Belgium (FWO Vlaanderen). J.Z. was supported by a KU Leuven grant (PF/10/ 005) to the Centre for Excellence of Generalization Research in Ill Health and Psychopathology granted to J.V. and I.V.D., a PDM grant of the KU Leuven research council, and an "Asthenes" long-term structural funding (METH/15/011)-Methusalem grant by the Flemish Government (granted to J.V. and I.V.D.). The authors have no conflicts of interests to report.

\section{REFERENCES}

1. Madden VJ, Harvie DS, Parker R, Jensen KB, Vlaeyen JW, Moseley GL, Stanton TR. Can pain or hyperalgesia be a classically conditioned response in humans? A systematic review and meta-analysis. Pain Med 2016;17:1094-111.

2. Colloca L, Sigaudo M, Benedetti F. The role of learning in nocebo and placebo effects. Pain 2008; 136:211-8.

3. Petersen GL, Finnerup NB, Colloca L, Amanzio M, Price DD, Jensen TS, Vase L. The magnitude of nocebo effects in pain: a meta-analysis. Pain 2014;155:1426-34.

4. Corsi N, Colloca L. Placebo and nocebo effects: the advantage of measuring expectations and psychological factors. Front Psychol 2017;8:308. 
5. Wiech K. Deconstructing the sensation of pain: the influence of cognitive processes on pain perception. Science 2016;354:584-7.

6. Wiech K, Vandekerckhove J, Zaman J, Tuerlinckx F, Vlaeyen JW, Tracey I. Influence of prior information on pain involves biased perceptual decision-making. Curr Biol 2014;24:R679-81.

7. Zaman J, Vlaeyen JW, Van Oudenhove L, Wiech K, Van Diest I. Associative fea learning and perceptual discrimination: a perceptual pathway in the development of chronic pain. Neurosci Biobehav Rev 2015;51:118-25.

8. Wiech K, Lin CS, Brodersen KH, Bingel U, Ploner M, Tracey I. Anterior insula integrates information about salience into perceptual decisions about pain. J Neurosci 2010;30:16324-31.

9. Oka S, Chapman CR, Kim B, Shimizu O, Noma N, Takeichi O, Imamura Y, Oi Y Predictability of painful stimulation modulates subjective and physiological responses. J Pain 2010;11:239-46.

10. Yoshida W, Seymour B, Koltzenburg M, Dolan RJ. Uncertainty increases pain evidence for a novel mechanism of pain modulation involving the periaqueductal gray. J Neurosci 2013;33:5638-46.

11. Brown CA, Seymour B, Boyle Y, El-Deredy W, Jones AK. Modulation of pain ratings by expectation and uncertainty: behavioral characteristics and anticipatory neural correlates. Pain 2008;135:240-50.

12. Zaman J, Vanpaemel W, Aelbrecht C, Tuerlinckx F, Vlaeyen JW. Biased pain reports through vicarious information: a computational approach to investigate the role of uncertainty. Cognition 2017;169:54-60.

13. Clark JA, Brown CA, Jones AK, El-Deredy W. Dissociating nociceptive modulation by the duration of pain anticipation from unpredictability in the timing of pain. Clin Neurophysiol 2008;119:2870-8.

14. Wiecki TV, Sofer I, Frank MJ. HDDM: hierarchical Bayesian estimation of the drift-diffusion model in Python. Front Neuroinform 2013;7:14.

15. Vandekerckhove J, Tuerlinckx F, Lee MD. Hierarchical diffusion models for twochoice response times. Psychol Methods 2011;16:44-62.

16. Yarnitsky D, Sprecher E, Zaslansky R, Hemli JA. Heat pain thresholds: normative data and repeatability. Pain 1995;60:329-32.
17. Blumenthal TD, Cuthbert BN, Filion DL, Hackley S, Lipp OV, van Boxtel A. Committee report: guidelines for human startle eyeblink electromyographic studies. Psychophysiology 2005;42:1-15.

18. Ratcliff R, McKoon G. The diffusion decision model: theory and data for twochoice decision tasks. Neural Comput 2008;20:873-922.

19. Zaman J, Madden VJ, Iven J, Wiech K, Weltens N, Ly HG, Vlaeyen JW, Van Oudenhove L, Van Diest I. Biased intensity judgements of visceral sensations after learning to fear visceral stimuli: a drift diffusion approach. J Pain 2017; 18:1197-208

20. Ratcliff R. A diffusion model account of response time and accuracy in a brightness discrimination task: fitting real data and failing to fit fake but plausible data. Psychon Bull Rev 2002;9:278-91.

21. Voss A, Rothermund K, Voss J. Interpreting the parameters of the diffusion model: an empirical validation. Mem Cognit 2004;32:1206-20.

22. Mulder MJ, Wagenmakers E-J, Ratcliff R, Boekel W, Forstmann BU. Bias in the brain: a diffusion model analysis of prior probability and potential payoff. J Neurosci 2012;32:2335-43.

23. Ratcliff R, Tuerlinckx F. Estimating parameters of the diffusion model: approaches to dealing with contaminant reaction times and parameter variability. Psychon Bull Rev 2002;9:438-81.

24. Verdonck $S$, Tuerlinckx F. Factoring out nondecision time in choice reaction time data: theory and implications. Psychol Rev 2016;123:208-18.

25. Meulders A, Vansteenwegen D, Vlaeyen JW. The acquisition of fear of movement-related pain and associative learning: a novel pain-relevant human fear conditioning paradigm. Pain 2011;152:2460-9.

26. Hermans D, Craske MG, Mineka S, Lovibond PF. Extinction in human fear conditioning. Biol Psychiatry 2006;60:361-8.

27. Williams AE, Rhudy JL. The influence of conditioned fear on human pain thresholds: does preparedness play a role? J Pain 2007;8:598-606.

28. Koyama T, McHaffie JG, Laurienti PJ, Coghill RC. The subjective experience of pain: where expectations become reality. Proc Natl Acad Sci U S A $2005 ; 102: 12950-5$. 